\title{
Correlations of Handgrip Strength with Selected Anthropometric Variables and Flexibility Measure in Indian Inter-university Handball Players
}

\author{
Shyamal Koley and Aanchal \\ Department of Sports Medicine and Physiotherapy, Guru Nanak Dev University, Amritsar 143005, Punjab, India
}

\begin{abstract}
The purpose of this study was of two-fold: firstly to estimate the handgrip strength of Indian inter-university handball players and, secondly to search the correlations of it with selected anthropometric variables and flexibility measure. To serve this purpose, a total of eight anthropometric variables, such as height, weight, body mass index, upper arm length, forearm length, total arm length, hand length and hand breadth, flexibility measure such as, sit and reach test, and right and left handgrip strength were measured on purposely selected 150 Indian inter-university handball players aged 18-25 years collected from the inter-university competition held in Guru Nanak Dev University, Amritsar, India during September, 2013. An adequate number of controls $(n=102)$ were also taken from the same place for comparisons. The results showed statistically significant between-group differences $(P \leq 0.006-0.001)$ among the male and female handball players and controls in all the variables studied. Statistically significant positive correlations $(P \leq$ 0.023-0.001) of both right and left handgrip strength were found with all the variables studied, except BMI, in Indian inter-university handball players. In conclusion, it may be stated that handgrip strength may be used as one of the indicating factors for physical strength as well as the flexibility measure of the handball players.
\end{abstract}

Key words: Handgrip strength, anthropometric variables, physical fitness tests, Indian inter-university handball players.

\section{Introduction}

Handball is a team game. It requires a high standard of preparation to achieve success [1]. The movement patterns of this game are characterized as intermittent and they change continuously in response to different offensive and defensive situations. Anthropometric and morphological characteristics can influence the effectiveness of such responses, as has been observed in other sports [2]. In handball, players require to have well developed aerobic and anaerobic capacities [3]. Anthropometry has been defined as the measurement of morphological parameters of human [4]. It was reported that a battery of anthropometric and morphological tests could distinguish between players of different ability in the same sport [5-7].

Handgrip strength is often used as an indicator of overall physical strength of an individual [8], hand and

Corresponding author: Shyamal Koley, Ph.D., professor, research field: kinanthropometry. forearm muscles performances [9], as a functional index of nutritional status [10-15] and physical performance [16]. Handgrip strength is a physiological variable that is affected by a number of factors including age, gender and body size. Strong correlations between grip strength and various anthropometric traits, (weight, height, hand length etc.) were reported earlier [11, 12, 17-21].

Some literature related to the handgrip strength, morphological and anthropometric variables of handball players are available [22-26]. Literature related to its association of handgrip strength with anthropometric variables in handball players is scanty, especially in Indian context. Thus, the present study was planned with the objectives to estimate the handgrip strength and its correlations with selected anthropometric variables and flexibility measure in inter-university handball players of both the sexes. 


\section{Materials and Methods}

The present cross-sectional study was based on purposely selected 150 inter-university level handball players ( 75 males, mean age $18.6 \pm 0.7$ years and 75 females, mean age $18.9 \pm 1.03$ years) aged $18-25$ years from the inter-university competition organized in Guru Nanak Dev University, Amritsar, Punjab, India in March, 2014. An adequate number of controls $(n=102$, 52 males, mean age $22.4 \pm 1.69$ years, and 50 females, mean age $20.8 \pm 2.25$ years). The age of the subjects were recorded from the date of birth registered in their respective records submitted to the authorities. A written consent was obtained from the subjects. The data were collected under natural environmental conditions in morning (between 8 am to 12 noon). The study was approved by the institutional ethical committee.

\subsection{Anthropometric Measurements}

Eight anthropometric variables, such as height (HT), weight (WT), body mass index (BMI), upper arm length (UAL), forearm length (FAL), total arm length (TAL), hand length (HL), hand breadth (HB) were measured on each subject using standard techniques [27].

The height was recorded during inspiration using a stadiometer (Holtain Ltd., Crymych, Dyfed, UK) to the nearest $0.1 \mathrm{~cm}$. Weight was measured by digital standing scales (Model DS-410, Seiko, Tokyo, Japan) to the nearest $0.1 \mathrm{~kg}$. BMI was then calculated using the formula weight $(\mathrm{kg}) /$ height $^{2}(\mathrm{~m})^{2}$. Upper arm length, forearm length and total arm length was measured by first segment of anthropometer in centimeter. Hand length and hand breadth was measured by sliding caliper in centimeter.

\subsection{Handgrip Strength Measurement}

The grip strength of both right and left hands was measured using a standard adjustable digital handgrip dynamometer (Takei Scientific Instruments Co., LTD, Japan) at standing position with shoulder adducted and neutrally rotated and elbow in full extension. The dynamometer was held freely without support, not touching the subject's trunk. The position of the hand remained constant without the downward direction. The subjects were asked to put maximum force on the dynamometer thrice with 30 seconds recovery period from both sides of the hands. The maximum value was recorded in kilograms.

\subsection{Flexibility Measure (Sit and Reach Test)}

Sit and reach test was used to estimate back and hamstring flexibility. The players performed warm up for 10 minutes and then removed their shoes for test. The researcher secured the ruler to the box top with the tape so that the front edge of the box lined up with the zero-mark on the ruler and the zero-end of the ruler pointed towards the player. The players were asked to sit on the floor with their legs fully extended with the bottom of their bare feet against the box. The players placed one hand on top of the other, slowly bent forward and reached along the top of the ruler as far as possible holding the stretch for two seconds. The researcher recorded the distance reached by the players' finger tips in $\mathrm{cm}$. The players performed the test thrice. The researcher then calculated and recorded the average of the three distances and assessed the players' performance.

\subsection{Statistical Analysis}

Standard descriptive statistics (mean \pm standard deviation) were determined for directly measured variables. One way analysis of variance was tested for the comparisons of data among inter-university handball players. Pearson's correlation coefficients were applied to establish the correlations of right and left handgrip strength with the variables measured. Data were analyses using SPSS (Statistical Package for Social Science) version 17.0. A 5\% level of probability was used to indicate statistical significance.

\section{Results}

Table 1 showed the descriptive statistics of 
anthropometric variables and flexibility measure in inter-university handball players and controls. The one way analysis of variance of handgrip strength, anthropometric variables and flexibility measure tests showed statistically significant between-group differences $(P<0.006-0.001)$ in all the variables studied. Significant sex differences $(P<0.023-0.001)$ were also noted in all the variables studied both in handball players and controls.

The correlation coefficients of right and left handgrip strength with the selected anthropometric variables and flexibility measure in inter-university handball players were shown in Table 2. In the players, significantly positive correlations $(P<0.001)$ of both right and left handgrip strength were found with all the variables studied, except BMI. In controls, significantly positive correlations $(P<0.023-0.001)$ of right and left handgrip strength were noted with all the variables studied, except upper arm length with left handgrip strength.

\section{Discussion}

Ball games require comprehensive ability including physical, technical, mental, and tactical abilities. Among them, physical abilities of players exert marked effects on the skills of the players themselves and the tactics of the team, because ball games demand repeated maximum exertion such as running and throwing.

Table 1 One way ANOVA of handgrip strength, anthropometric variables and flexibility measure in Indian inter-university handball players.

\begin{tabular}{|c|c|c|c|c|c|c|c|c|c|c|}
\hline \multirow[t]{2}{*}{ Variables } & \multicolumn{2}{|c|}{$\begin{array}{c}\text { Male handball } \\
\text { players }(n=75)\end{array}$} & \multicolumn{2}{|c|}{$\begin{array}{c}\text { Female handball } \\
\text { players }(n=75)\end{array}$} & \multicolumn{2}{|c|}{$\begin{array}{c}\text { Male } \\
\text { controls }(n=52)\end{array}$} & \multicolumn{2}{|c|}{$\begin{array}{c}\text { Female } \\
\text { controls }(n=50)\end{array}$} & \multirow[t]{2}{*}{ F value } & \multirow[t]{2}{*}{$P$ value } \\
\hline & Mean & SD & Mean & SD & Mean & SD & Mean & SD & & \\
\hline $\mathrm{HT}(\mathrm{cm})$ & 171.43 & 5.55 & 161.15 & 5.88 & 170.62 & 5.87 & 159.17 & 6.05 & 72.843 & 0.001 \\
\hline WT (kg) & 62.60 & 7.13 & 87.15 & 3.26 & 64.37 & 11.02 & 51.83 & 8.96 & 29.739 & 0.001 \\
\hline BMI & 21.28 & 2.39 & 21.99 & 1.19 & 22.15 & 3.55 & 20.46 & 3.80 & 4.295 & 0.006 \\
\hline UAL (cm) & 34.36 & 1.88 & 29.21 & 1.20 & 28.77 & 2.91 & 28.19 & 2.49 & 124.399 & 0.001 \\
\hline FAL $(\mathrm{cm})$ & 32.58 & 1.89 & 27.15 & 0.95 & 27.71 & 3.47 & 26.04 & 1.87 & 126.600 & 0.001 \\
\hline TAL (cm) & 86.36 & 2.13 & 71.48 & 2.11 & 75.04 & 3.82 & 70.82 & 3.75 & 429.222 & 0.001 \\
\hline $\mathrm{HL}(\mathrm{cm})$ & 19.42 & 2.62 & 15.12 & 1.58 & 19.02 & 0.70 & 17.03 & 0.87 & 90.913 & 0.001 \\
\hline $\mathrm{HB}(\mathrm{cm})$ & 8.19 & 0.30 & 7.01 & 0.22 & 8.55 & 0.40 & 7.49 & 0.37 & 296.270 & 0.001 \\
\hline $\mathrm{S} \& \mathrm{RT}(\mathrm{cm})$ & 15.51 & 1.71 & 11.71 & 3.40 & 6.19 & 6.07 & 0.66 & 8.13 & 100.703 & 0.001 \\
\hline RHGS (kg) & 36.47 & 5.02 & 24.56 & 4.62 & 41.11 & 6.57 & 24.25 & 4.24 & 163.034 & 0.001 \\
\hline LHGS (kg) & 37.22 & 4.50 & 23.35 & 5.38 & 38.61 & 6.39 & 22.45 & 4.18 & 174.270 & 0.001 \\
\hline
\end{tabular}

HT = height, WT = weight, BMI = body mass index, UAL = upper arm length, FAL = forearm length, TAL = total arm length, HL = hand length, HB = hand breadth, S\&RT = sit and reach test, RHGS = right handgrip strength and LHGS = left handgrip strength.

Table 2 Correlation coefficients of right and left handgrip strength with anthropometric variables and flexibility measure in handball players.

\begin{tabular}{|c|c|c|c|c|c|c|c|c|}
\hline \multirow{3}{*}{ Variables } & \multicolumn{4}{|c|}{ Right handgrip strength } & \multicolumn{4}{|c|}{ Left handgrip strength } \\
\hline & \multicolumn{2}{|c|}{ Handball players } & \multicolumn{2}{|c|}{ Controls } & \multicolumn{2}{|c|}{ Handball players } & \multicolumn{2}{|c|}{ Controls } \\
\hline & $r$ & $P$ & $r$ & $P$ & $r$ & $P$ & $r$ & $P$ \\
\hline HT & 0.666 & 0.001 & 0.704 & 0.001 & 0.687 & 0.001 & 0.685 & 0.001 \\
\hline WT & 0.506 & 0.001 & 0.603 & 0.001 & 0.529 & 0.001 & 0.628 & 0.001 \\
\hline BMI & -0.110 & 0.180 & 0.293 & 0.003 & -0.104 & 0.205 & 0.328 & 0.001 \\
\hline UAL & 0.745 & 0.001 & 0.218 & 0.028 & 0.857 & 0.001 & 0.132 & 0.186 \\
\hline FAL & 0.752 & 0.001 & 0.321 & 0.001 & 0.768 & 0.001 & 0.327 & 0.001 \\
\hline TAL & 0.500 & 0.001 & 0.780 & 0.001 & 0.466 & 0.001 & 0.801 & 0.001 \\
\hline HL & 0.478 & 0.001 & 0.656 & 0.001 & 0.505 & 0.001 & 0.643 & 0.001 \\
\hline $\mathrm{HB}$ & 0.757 & 0.001 & 0.691 & 0.001 & 0.795 & 0.001 & 0.398 & 0.001 \\
\hline S\&RT & 0.552 & 0.001 & 0.396 & 0.001 & 0.588 & 0.001 & 0.388 & 0.001 \\
\hline
\end{tabular}


Therefore, players must have the physical abilities to make rapid and powerful movements along with aerobic and anaerobic capacities that make them competent in prolonged vigorous offensive and defensive maneuvers [28].

Handball is one of the team sports in the Olympic Games. It requires a high standard of physical endurance in order to compete 60 minutes of highly competitive play and to excel the performance [3]. In handball, movement patterns are characterized as intermittent and change continuously in response to different playing situations. Anthropometric and morphological characteristics can obviously influence the effectiveness of such responses [28-31].

In the present study, one way analysis of variance showed statistically significant between-group differences of right and left handgrip strength with selected anthropometric variables and flexibility measure. When comparisons were made between the players and their control counterparts, both in male and female players, significant differences were observed in almost all the variables studied. These differences were probably due to the effect of regular physical exercise and vigorous training program in handball players. Further, significant sex differences were found in all the variables in the handball players. These differences were probably due to structural and functional differences between two sexes.

Significant positive correlations of both right and left handgrip strength were found with all the variables studied. Such type of correlations of handgrip strength with anthropometric variables and performance tests were also reported in other sports too [18-21]. In fact, all the hand and arm muscles are responsible for the generation of handgrip force and, the hand and arm anthropometry has a close affinity to handgrip strength [32]. In the present study, small sample size was a limitation which would be taken into account in our future studies.

\section{Conclusions}

The findings of the present study have immense practical application in selection of talents in handball players. It would be beneficial to the handball players in term of optimizing training programs separately for male and female players.

\section{References}

[1] Hasan, A. A., Reilly, T., Cable, N. T., and Ramadan, J. 2007a. "Anthropometric Profiles of Elite Asian Female Handball Players" The Journal of Sports Medicine and Physical Fitness 47 (2): 197-202.

[2] Deng, P. L., Lin, Z. H. R., Xia, H. Q., and Cheng, Y. H. 1990. "A Study of Somatotypes of Chinese Elite Handball Players." J. China Sports Sci. Soc. 10: 48-53.

[3] Delamarce, P., Gratas, A., Beillot, J., Dassonville, J., Rochcongar, P., and Lessard, Y. 1987. "Extent of Lactic Anaerobic Metabolism in Handballers." Int. J. Sports Med. 8 (1): 55-9.

[4] Ross, W. D., Drinkwater, D. T., Bailey, D. A., Marshall, G. R., and Leahy, R. M. 1980. "Kinanthropometry; Traditions and New Perspective." In Kinanthropometry II. International Series on Sports Science, edited by Ostyn, M., Beunen, G., and Simons, J. Vol. 9. Baltimore: University Park Press, 3-27.

[5] Keogh, J. 1999. "The Use of Physical Fitness Scores and Anthropometric Data to Predict Selection in an Elite Under-18 Australian Rules Football Team." Journal of Sports Science \& Medicine 2 (2): 125-33.

[6] Claessens, A. L., Lefevre, J., Beunen, G., and Malina, R. M. 1999. "The Contribution of Anthropometric Characteristics to Performance Scores in Elite Female Gymnasts." Journal of Sports Medicine and Physical Fitness 39 (4): 355-60.

[7] Slater, G. J., Rice, A. J., Mujika, I., Hahn, A. G., Sharp, K., and Jenkins, D. G. 2005. "Physique Traits of Lightweight Rowers and Their Relationship to Competitive Success." British Journal of Sports Medicine 39 (10): 736-41.

[8] Foo, L. H. 2007. "Influence of Body Composition, Muscle Strength, Diet and Physical Activity on Total Body and Forearm Bone Mass in Chinese Adolescent Girls." British Journal of Nutrition 98 (6): 1281-7.

[9] Nwuga, V. 1975. "Grip Strength and Grip Endurance in Physical Therapy Students." Archives of Physical Medicine \& Rehabilitation 56 (7): 296-9.

[10] Jeejeebhoy, K. N. 1998. "Nutritional Assessment." Gastroentrology Clinics of North America 27 (2): 347-69. 
[11] Jurimae, T., Hurbo, J., and Jurimae, J. 2009. "Relationship of Handgrip Strength with Anthropometric and Body Composition Variables in Prepubertal Children." Journal of Comparative Human Biology 60 (3): 225-38.

[12] Kaur, N., and Koley, S. 2010. "An Association of Nutritional Status and Handgrip Strength in Female Laborers and Sedentary Women of Jalandhar, Punjab, India." Anthropologist 12 (4): 237-43.

[13] Pieterse, S., Manandhar, M., and Ismail, S. 2002. "The Association between Nutritional Status and Hand Grip Strength in Older Rwandan Refugees." European Journal of Clinical Nutrition 56 (10): 933-9.

[14] Tsunawake, N., Tahara, Y. Moji, K., Muraki, S., Minowa, K., and Yukawa, K. 2003. "Body Composition and Physical Fitness of Female Volleyball and Basketball Players of the Japan Inter-high School Championship Teams." Journal of Physiological Anthropology \& Applied Human Science 22 (4): 195-201.

[15] Watters, D. A., Haffejee, A. A., Angom, I. B., and Duffy, K. J. 1985. "Nutritional Assessment by Hand Grip Dynamometry." South African Medical Journal 68 (Jul.-Dec.): 585-7.

[16] Samson, M. M., Meeuwsen, B. I., Crowe, A., Dessens, J. E., Duursma, S. A., and Verhaar, H. J. 2000. "Relationships between Physical Performance Measures, Age, Height and Body Weight in Healthy Adults." Age and Ageing 29 (3): 235-42.

[17] Ross, C. H., and Rösblad, B. 2002. "Norms for Grip Strength in Children Aged 4-16 Years." Acta Paediatrica 91 (6): 617-25.

[18] Bohannon, R. W. 1997. "Reference Values for Extremity Muscle Strength Obtained by Handheld Dynamometer from Adults Aged 20 to 79 Years." Archives of Physical Medicine \& Rehabilitation 78 (1): 26-32.

[19] Koley, S., and Yadav, M. K. 2009. "An Association of Handgrip Strength with Some Anthropometric Variables in Indian Cricket Players." FACTA UNIVERSITATIS, Series: Physical Education \& Sports 7 (2): 113-23.

[20] Koley, S., Kaur, N., and Sandhu, J. S. 2009. "Association of Hand Grip Strength and Some Anthropometric Traits in Female Laborers of Jalandhar, Punjab, India." Journal of Life Sciences 1 (1): 57-62.

[21] Koley, S., Singh, J., and Sandhu, J. S. 2010. "Anthropometric and Physiological Characterictics on Indian Inter-university Volleyball Players." Journal of Human Sport \& Exercise 5 (3): 389-99.
[22] Matthys, S. P. J., Fransen, J., Vaeyens, R., Lenoir, M., and Philippaerts, R. 2013. "Differences in Biological, Anthropometry and Physical Performance between Playing Positions in Youth Team Handball." Journal of Sports Sciences 31 (12): 1344-52.

[23] Visnapuu, M., and Jürimäe, T. 2007. "Handgrip Strength and Hand Dimensions in Young Handball and Basketball Players." Journal of Strength and Conditioning Research 21 (3): 923-9.

[24] Smith, T., Smith, S., Martin, M., Henry, R., and Weeks, S. 2005. "Grip Strength in Relation to Overall Strength and Functional Capacity in Very Old and Oldest Females." Physical and Occupational Therapy in Geriatrics 24 (4): 63-78.

[25] Fry, A. C., Ciroslan, M. D., Fry, C. D., LeRoux, C. D., and Schilling, B. K. 2006. "Anthropometric and Performance Variables Discriminating Elite American Junior Men Weightlifters." Journal of Strength \& Conditioning Research 20 (4): 861-6.

[26] Yasuo, G., Daisaku, T., Nariyuki, M., Junya, S., Toshihiko, O., Masahiko, M., and Yashiyuki, M. 2005. "Relationship between Grip Strength and Surgical Results in Rotator Cuff Tears." Shoulder Joint 29 (3): 559-62.

[27] Lohmann, T. G., Roche, A. F., and Martorell, R. 1988. Anthropometric Standardization Reference Manual. Champaign, IL: Human Kinetics Books.

[28] Hasan, A. A. A., Rahaman, J. A., Cable, N. T., and Reilly, T. 2007b. "Anthropometric Profile of Elite Male Handball Players in Asia.” Biology of Sport 24 (1): 3-12.

[29] Srhoj, V., Marinovi, M., and Rogulj, N. 2002. "Position Specific Morphological Characteristics of Top-level Male Handball Players.” Coll. Antropol. 26 (1): 219-27.

[30] Skoufas, D., Kotzamanidis, C., Hatzikotoylas, K., Bebetsos, G., and Patikas D. 2003. "The Relationship between the Anthropometric Variables and Throwing Performance in Handball." J. Hum. Mov. Sci. 45 (1): 469-84.

[31] Zaparditis, I., Vareltzis, I., Gouvali, M., and Kororos, P. 2009. "Physical Fitness and Anthropometric Characteristics in Different Levels of Young Team Handball Players." The Open Sport Sciences Journal 2 (1): 22-8.

[32] Koley, S., and Kaur, S. P. 2011. "Correlations of Handgrip Strength with Selected Hand-Arm-anthropometric Variables in Indian Inter-university Female Volleyball Players." Asian Journal of Sports Medicine 2 (4): 220-6. 